\title{
Política y estrategias narrativas en El nombre de la rosa (Umberto Eco)
}

\author{
Enrique C. Corti \\ Universidad Nacional de San Martín - \\ CONICET
}

\begin{abstract}
Resumen
En el siglo XIV irrumpen, en el pensamiento político medieval y como consecuencia de las disputas entre el emperador y el papado, ciertos pensadores que abordan una filosofía política nueva y opuesta a la precedente: Marsilio de Padua y Guillermo de Ockham fueron precursores, y para el mundo "moderno» su influencia ha sido decisiva.

En El nombre de la rosa (NR), es Guillermo de Baskerville quien presta voz a la incipiente doctrina política, y lo hace en consonancia con Marsilio y con Guillermo de Ockham. El artículo presenta el tema de la filosofía política en NR, en un marco de análisis del discurso y las estrategias narrativas de U. Eco en relación con los sentidos de la escritura.
\end{abstract}

\section{Palabras clave:}

- filosofía política · medioevo $\cdot$ discurso narrativo

\begin{abstract}
In the fourteenth century burst in medieval political thought and as a result of disputes between the emperor and the papacy, certain thinkers who address a new and opposite to the previous political philosophy: Marsilio of Padua and William of Ockham were precursors. For the «modern» world their influence has been decisive.In The Name of the Rose (NR) is William of Baskerville who lends voice to the emerging political doctrine, and does so in line with Marsilio and William of Ockham. The paper presents the theme of political philosophy in NR, within a framework of discourse analysis and narrative strategies in relation to the senses of writing.
\end{abstract}

\section{Key words:}

political philosophy · middle ages · narrative

\footnotetext{
- Nacido en Santa Fe, 1953. Investigador en Conicet y profesor de Filosofía Medieval y de Metafísica en la Universidad Nacional de San Martín. Se ocupa de la ontología y la filosofía del lenguaje en la Edad Media de tradición agustiniana y especialmente del pensamiento de Anselmo de Canterbury. Autor de El lenguaje y los límites (Unsam Edita, Buenos Aires, 2010), en torno al pensamiento especulativo de Anselmo y coautor de Lenguaje, lógica y ontología en cinco pensadores medievales (Baudino, Buenos Aires, 2012) y Oír, Entender, Argumentar (Miño y Dávila, Buenos Aires, 2016).
} 


\section{Política}

\subsection{Los hechos: Guillermo en El nombre de la rosa}

En el siglo XIV irrumpen, en el escenario del pensamiento político del medioevo y como consecuencia de las luchas entre los partidarios del emperador y el papado, ciertos pensadores que abordan una filosofía política extraña y opuesta a la precedente aún en vigencia: Marsilio de Padua y después Guillermo de Ockham, consejeros del emperador Luis de Baviera, fueron sus precursores. Para el mundo «moderno» constituyeron pensadores cuya influencia ha sido decisiva.

En El nombre de la rosa, es Guillermo de Baskerville quien presta su voz a la incipiente doctrina política, y lo hace en consonancia con Marsilio, maestro en Padua, y con Guillermo de Ockham, de quien es homónimo: «Más tarde conocí a Marsilio, me atrajeron sus ideas sobre el imperio, sobre el pueblo, sobre una nueva ley para los reinos de la tierra, y así acabé formando parte del grupo de hermanos nuestros que están aconsejando al emperador» (Eco, [1980] 1985:78).

Para Guillermo no cabe la posibilidad de aplicar las ideas de Marsilio en una época como la suya, es decir la época en que Eco sitúa ficcionalmente al personaje; esas ideas son utópicas para tal momento: «Marsilio sueña con una transformación que en estos momentos no es posible» (422). Pocas de esas ideas son expresadas en el discurso pronunciado por Guillermo ante los enviados de Avignon acerca de «una extraña concepción del gobierno temporal». Los enviados sin excepción, pero también algunos de los allí presentes —el Abad Abbone, por ejemplo— no pudieron disimular el desagrado que les producían las palabras del orador: «No sólo los aviñoneses se agitaban ahora con la ira pintada en el rostro y haciendo comentarios por lo bajo, sino que también al propio abad aquellas palabras parecían haberle causado una impresión desfavorable, como si pensase que no era así como había imaginado las relaciones entre su orden y el imperio. En cuanto a los franciscanos, Michele da Cesena estaba perplejo; Girolamo, aterrado; Ubertino, pensativo» (435). Extrañas resultaron para Adso de Melk las palabras del discurso de su maestro y mentor; airadas fueron las reacciones de malestar que produjo en un auditorio encuadrado en coordenadas filosóficas-políticas vigentes en los inicios del s. XIV. Bernardo Gui lo desafió a presentar el discurso reciente ante el pontífice de Aviñón; el cardenal Del Poggetto propuso lo mismo; Guillermo, después de pensarlo y manifestarse plenamente convencido por Bernardo, respondió: «No iré». Al comenzar el siglo XIV, las ideas filosóficas-teológicas-políticas vigentes sostienen que el Papa —como sucesor del apóstol Pedro- tiene el poder y la obligación de dirigir el pueblo de los creyentes, es decir la comunidad que es iglesia. Su función es equiparable a la de un monarca que gobierna su reino, y la irradiación de jerarquías eclesiásticas emanadas desde el ápice de la iglesia, encarnado en el Papa, garantiza orden y paz en toda la comunidad, orden que se mantiene a condición de que todos y cada uno de los miembros de dicha comunidad se mantengan dentro de los límites inherentes a la función que se les ha asignado en jerarquía. Las leyes promulgadas por el Papa de acuerdo con sus funciones jurisdiccionales supremas son los medios para el desempeño de su función. Estas leyes tienen legitimidad universal e incumbencia en todo tema relacionado con la estructura de la comunidad cristiana. Únicamente el Papa puede decidir qué afecta — bien o mal— la comunidad: ni los asuntos ni los gobernantes meramente temporales poseen una posición independiente y autónoma. 
La unidad de la comunidad cristiana exige unidad de gobierno cuya manifestación visible es la monarquía papal. El pontífice ejerce su autoridad sobre los príncipes de modo directo en los asuntos espirituales e indirectamente en los asuntos sociales y políticos, como derivación del poder espiritual. Sin embargo, la jurisdicción papal sólo es apelada cuando los intereses básicos de su comunidad lo reclama. Inocencio III (1198-1216) es quien formula este principio al definir que las cuestiones feudales como tales quedan al margen de la jurisdicción del Papa, quien sólo asume plena injerencia cuando asoma cualquier indicio de pecado. Sostiene que - ratione et occasione peccati - el Papa puede intervenir en ciertas causas llegando, si fuese necesario, a desposeer a un príncipe de su reino y coronar un nuevo rey; él es quien juzga cuándo se está ante indicios de pecado.

El conflicto entre el papado y los reyes encontró su culminación en Marsilio de Padua y Guillermo de Ockham, pero se desarrolló en el medio propicio de los enfrentamientos entre Luis de Baviera y Juan XXII. Este conflicto es el último entre los emperadores germánicos y los Papas. Juan XXII se creyó poseedor de derecho a una hegemonía universal de manera semejante a Gregorio VII, Inocencio III y Bonifacio VIII. En pos de tal hegemonía se enfrentó con el emperador y su intento lo condujo a fracasar. Al morir el emperador Enrique VII en 1313 y requerirse designar sucesor, los electores se dividieron unos a favor de Federico de Austria y otros, de Luis de Baviera. La sede pontificia quedó vacante hasta 1316, cuando Juan XXII accede a ella en una elección tensa y violenta que Eco describe en su novela sin alterar los acontecimientos históricos.

\subsection{El nombre de la rosa en los hechos:}

Guillermo de Ockham

Guillermo de Ockham no abordó las relaciones entre el poder civil y el ecleciástico hasta su época de München. Si sus obras filosóficas-teológicas se sitúan antes de abandonar Avignon en 1328, sus escritos sobre política son posteriores. Hacia 1333-1334 con Opus nonaginta dierum inicia su polémica: ya se habían consumado los hechos decisivos de la coronación imperial de Luis de Baviera y el nombramiento de un antipapa. El pensamiento de Ockham se manifestó con gran claridad y moderación en sus dos obras más maduras: Breviloquium de principatu tyrannico super divina et humana (1342) y en De imperatorum et pontificum potestate (1347), última exposición y síntesis sobre política eclesiástica.

Contra el monismo de la potestad política, Ockham es partidario de la teoría de dos potestades ordenadas en recíproca dependencia. Invoca la autonomía de la potestad civil. En efecto, sostiene, hubo orden legítimo antes de Cristo y de la Iglesia; el imperio no fue legitimado por primera vez en el bautismo de Constantino; el imperio gentil romano ya poseía verdadera jurisdicción y fue reconocido por Cristo y los Apóstoles. De la ordenación divina deriva tanto la propiedad privada como el poder de instituir soberanos que tengan poder secular de gobernar. Tanto de parte de Dios como de la naturaleza todos los mortales nacidos libres tienen el derecho de elegirse libremente un gobernante. La potestad de legislar estuvo primero y originariamente en el pueblo, que la cedió al César, sin que esta cesión signifique 
renunciar a negarle obediencia en algún momento determinado. El poder de los príncipes no es ilimitado, encuentra límites en las libertades del hombre (que son anteriores al Estado) y en el bien común para el que fue instituido.

La Iglesia como comunidad de creyentes es gobernada, por voluntad de Cristo, monárquicamente: Cristo eligió a Pedro como su vicario. A diferencia de Marsilio, Ockham concede al Papa "potestad real transferida por Cristo»; de no ser así, Cristo no hubiera cuidado suficientemente de su Iglesia. Sin embargo, Cristo no le dio a Pedro la plenitud de la potestad en lo temporal ni en lo espiritual. De habérsela dado in temporalibus, nos hubiera hecho a todos esclavos; también la potestad espiritual tiene sus límites, a los que hay que reducir de nuevo a la Iglesia de Avignon. El Papa puede ordenar todo lo que no repugne al mandamiento divino y al derecho natural. Debe, por ejemplo, respetar los títulos legítimos de los reyes, fieles o infieles. El poder del Papa sólo se extiende a lo necesario para la salud de las almas. «Todo lo demás, aun cuando fuere espiritual, no debe mandarlo, para que la ley del evangelio no se convierta en ley de servidumbre». El poder del Papa no es de dominación, sino de servicio. Puede intervenir en el orden civil: en caso de necesidad, cuando faltan o fallan las autoridades competentes, puede y debe el Papa, por razón del bien común, intervenir en los asuntos temporales. Sin emplear la expresión, defiende Ockham la doctrina de la potestas indirecta in temporalibus. También, en caso de necesidad, el emperador puede intervenir en el orden eclesiástico: puede convocar un concilio y hasta deponer al Papa: no en razón de ser emperador, sino miembro creyente de la Iglesia.

Guillermo de Baskerville es la voz narrativa del Venerabilis Inceptor, una de cuyas refutaciones recae sobre la tesis «el romano pontífice tiene más poder sobre el imperio que sobre los demás reinos». Veía Ockham que en tal caso los Papas, que entendían ser intermediarios en la concesión del poder temporal a los emperadores, no los consideraban más que altos funcionarios de la estructura jerárquica papal de gobierno. Al respecto, Guillermo de Baskerville expresa «sería muy extraño que el Papa tuviese jurisdicción sobre las cosas del imperio» y «el Papa no tiene sobre el imperio más derechos que sobre los otros reinos que, como no están sujetos a la aprobación del Papa ni el rey de Francia ni el sultán, no se ve por qué sí debe estarlo el emperador de los alemanes y de los italianos» (434). Esta doctrina que Eco pone en boca de Guillermo corresponde a «Breviloquium de potestate papae». En el libro IV de esta obra, las tesis de Ockham son: a) El imperio romano fue un imperio legítimo con autoridad propia recibida de Dios a través del pueblo, sin que tuviera que ser legitimado por Pedro y sus sucesores. ${ }^{1}$ La Escritura da sustento para afirmar el reconocimiento del imperio romano por parte de Cristo y de los Apóstoles. ${ }^{2}$ Por lo tanto no tenía sustento en la Escritura afirmar que el emperador romano hubiese recibido su legitimación del Papa, ni que la tuviese en mayor medida que otros reyes. ${ }^{3}$ b) En analogía con su convicción de la independencia del poder del emperador romano, traslada Ockham dicha convicción al siglo XIV y sostiene que el Papa no posee mayor poder sobre el imperio romano-germánico que sobre los otros reinos. ${ }^{4}$

En NR, durante la reunión de legaciones que recibe Abbone en su Abadía de Melk, Guillermo de Baskerville cierra su intervención con una mención directa de la pobreza de Cristo. Tan relacionados están, a su juicio, la pobreza de Cristo con la falta de jurisdicción en los asuntos temporales, que ambas mutuamente se condicionan.

Si Cristo vivió en la pobreza, no tuvo ningún poder en asuntos temporales; y si Cristo no tuvo poder alguno en asuntos temporales, entonces debió vivir en 
la pobreza. Los miembros de la legación papal de Avignon, como es sabido, no aceptan la pobreza real de Cristo, y Guillermo de Baskerville argumenta a partir de una verdad que los delegados papales aceptan: la falta de poder por parte de Cristo en los asuntos temporales (Eco, [1980] 1985:422 y 435). La idea de que el Papa no goza de la plenitud de poder en los asuntos temporales ni en los espirituales es una tesis reiterada por Ockham, pues si el Papa tuviese - instituidos por Cristo- potestad plena tanto en lo temporal cuanto en lo espiritual, sin excepción alguna interpuesta por ley divina ni por ley natural, la ley cristiana instituiría una servidumbre peor que la de la ley antigua. ${ }^{5}$

\section{Estrategias narrativas}

\subsection{La trama de El sabueso de los Baskerville}

La pelea entre el doctor Moriarty y Sherlock Holmes que termina con la caída de ambos contendientes en el despeñadero de la cascada, produjo generalizada indignación entre sus seguidores del Strand Magazine. Aparentemente habían muerto. Tal fue el clamor de los lectores, que así como Lope de Vega sentenció «el vulgo es necio, y pues lo paga, es justo», Conan Doyle comenzó a reconsiderar la continuidad de la saga que tanta fama consiguió para él. Sin embargo, Holmes había desaparecido, y él mismo detestaba el personaje de su invención, tanto cuanto estimaba al otro personaje suyo, el Brigadier Gerard, de cuya mano reconstruyó la Francia napoleónica en una suerte de crónica ficcional o novela histórica.

Es así que, en Norfolk y de un ocasional acompañante en esa oportunidad, Conan Doyle escucha una serie de leyendas supuestamente acontecidas en Dartmoor, en el Devonshire, donde se establece uno de los establecimientos penitenciarios más terribles de Inglaterra. La leyenda narraba una historia concerniente a un sabueso infernal que casi inmediatamente se convirtió en protagonista involuntario: una antigua familia del Devonshire, los Baskerville, sobre la cual pesaba una maldición espectral vinculada al famoso sabueso. Mr. Fletcher Robinson fue quien acompañaba al doctor Sir Arthur Conan Doyle en dicha oportunidad y a quien éste le concedió la coautoría del famoso relato donde, además, reaparecieron Holmes y, con él, su inseparable doctor Watson. Este relato es una curiosa mezcla de cierto "Walterscottismo» medieval y una dosis de realismo contemporáneo de esa época.

Cuando Sherlock Holmes, después de haber puesto en práctica todos sus métodos científicos aplicados a la investigación policial en El sabueso de los Baskerville sin éxito a la vista, y desolado por el aparente fracaso de su trabajo, recorre casi al descuido los retratos familiares que penden de la pared que respalda la escalera en la mansión Baskerville y reconoce lo parecido del rostro de Mr. Stapleton, de la casa de Merripit en la paramera, y alguien retratado en la galería de la escalera, de linaje Baskerville, la casualidad ilumina su problema. El tal Stapleton de la paramera es, en realidad, un descendiente bastardo de los Baskerville y, como tal, derechohabiente a la herencia de la familia que ha quedado en manos de Sir Henry of Baskerville, único descendiente socialmente legítimo. Lo demás pertenece a la historia de la narración: el éxito de la investigación corona tanto trabajo, resuelve el misterio y restaura la autoestima de Holmes. 
Tanto el «walterscottismo» medieval del relato de Conan Doyle cuanto la casualidad y el equívoco Stapleton/Baskerville que ayuda al detective a resolver el caso, son esenciales al personaje protagónico de NR. Lo primero condice con el clima espiritual y la época de la novela de Eco; lo último, con la impronta metodológica en la investigación del fraile franciscano y con su estado de ánimo.

Guillermo: - Huye, Adso, de los profetas y de los que están dispuestos a morir por la verdad (...). Jorge ha realizado una obra diabólica, porque era tal la lujuria con que amaba su verdad, que se atrevió a todo para destruir la mentira.

Adso:-Pero maestro, ahora habláis así porque os sentís herido en lo más hondo. Sin embargo, existe una verdad. La que habéis descubierto esta noche, la que encontraste interpretando las huellas que habíais leído durante los días anteriores. Jorge ha vencido, pero vos habéis vencido a Jorge, porque habéis puesto en evidencia su trama.

Guillermo: - No había tal trama, y la he descubierto por equivocación. (Eco, [1980] 1985:595)

\subsection{La cruz hic et nunc}

La posibilidad de la narración —escritura y lectura- y la posibilidad de historia en El nombre de la rosa (597) dependen de la cabal comprensión del uso que U. Eco hace de las expresiones temporales in principio e in fine (=cuando la verdad se manifieste a cara descubierta), únicos extremos entre los que cabe el trazo cruzado hic et nunc, es decir el trazo de la cruz entre narración e historia.

Así como Vico introduce el texto de su Ciencia Nueva (tanto en la edición de 1730 como en la de 1744) con una pintura alegórica que expone una imagen espacial de la historia (595), de semejante modo Eco prologa NR con una paráfrasis sobre el prólogo del evangelio de Juan para exponer una imagen espacial de la narración que acomete. En efecto, así como en la pintura alegórica viquiana el dios que rige la historia y cuyo ojo ve y hace ver - porque de él parte el rayo de luz que reflejado en la Metafísica desciende finalmente sobre Homero- es el dios previdente y providente, el dios de Isaac, de Abraham y de Jacob no menos que el dios de Platón, de la misma manera el dios de Eco, el del prólogo de Juan, el dios palabra que está junto a Dios porque él mismo es Dios, es sobre quien la historia es historia y sin él no puede aprehenderse la lógica de esa historia. Sin el orden providencial no hay historia rerum gestarum porque sin él no hay res gesta, no hay eventos, nada acontece.

Para que pueda ser narrado, hasta el más simple y elemental acaecimiento requiere que se presuponga ya un orden en el que este acaecer adviene a luz, cuando menos el orden temporal de pasado, presente y futuro. Si el pasado es pasado hoy, pero puede ser futuro después, ninguna historia es posible, ninguna historia es pensable. Como enseña Kant, no es el tiempo el que transcurre sino los fenómenos en él, porque de lo contrario debería transcurrir en un otro tiempo, en un orden superior.

La narración — como para Vico la historia — presupone la posibilidad de un «hablar escribiendo», la posibilidad de unos vocablos sonoros pertenecientes a una voz aún no articulada que es ella misma gesto. Como Platón en el Cratilo, tà pràgmata —es decir las cosas reales de la experiencia viva- y no tà onta —la abstracción objetiva del ente- son las que poseen phonè kai schêma, sonido y 
figura. Esta lengua gestual, corpórea, la de las cosas entendidas como tà pràgmata - constituida por phonè kai schêma - es la lengua de los dioses, aquella que Homero mismo reconoce como más antigua que la suya.

Sin embargo, la narración de la historia presupone el lenguaje de la ciencia fundado sobre la lógica, que nace de la separación del decir y su contenido, del gesto corpóreo y el decir, del decir y la praxis. Esta separación, en el texto de NR, es operada por el cruzamiento entre el hic espacial de la abadía sin nombre y el nunc temporal de los acontecimientos que en ella se suceden, hacia el siglo XIV. Sin tal cruzamiento la historia no sería historia; estaría tensa y fija, extendida entre el principio de los principios - dios palabra que pronuncia - y el final de los finales — dios palabra que convoca-, frente a lo cual sólo cabe nostalgia y resignación, nostalgia de un principio lejano en un tiempo sin tiempo, y resignación hacia un final que aparece como el abismo sin fondo de la divinidad desierta y silenciosa, esa divinidad en la que Adso de Melk desea perderse ya desde el comienzo de la narración (581-582) para reaparecer al término de la misma. Ese dios no puede ser conmovido por ningún "aquí y ahora»: Gott ist ein lautes Nichts, ihn rührt kein Nun noch Hier. ${ }^{6}$

Sin embargo hay historia y narración, hay palabra, hay separación de phonè y schêma, hay "aquí y ahora». Aun así Eco piensa —y lo hace explícito en sus Apostillas (Eco, [1984] 1987)— que hasta el lector más ingenuo de NR se topa con el hecho de la imposibilidad de «una historia». La aserción de Eco trae a colación lo sucedido con la geometría euclidiana y la reformulación negativa de su postulado quinto: decir que no es posible salir de NR con una historia, cabe entenderlo en alguno de los sentidos siguientes: o bien no hay historia, o bien hay más de una.

\section{3. ¿Imposibilidad de "historia» o de "una» historia?}

En El nombre de la rosa hay historia, la instaura Adso narrando. Y más de una. Tantas, cuantas tienen que ver con los laberintos posibles. Eco describe tres: el clásico, el rizomático y el moderno (Eco, [1980] 1985:606). El primero y el último son espaciales; el segundo no, es de índole temporal.

El primero es el de Teseo y la lectura lo desenreda fácilmente, es el hilo de Ariadna de sí mismo, es espacial. Basta leer el texto desde el principio hasta el final para desenredar su trama policial.

El segundo es posmoderno, temporal y holístico, no tiene entrada ni salida y cualquier punto puede conectarse con cualquier otro. Asemeja un rizoma donde el lector enreda su lectura si omite considerar el hic de la narración, si cree que es posible una narración en forma de laberinto sin espacio. Este laberinto está tendido entre el principio de los principios y el final de los finales. Nada cabe, no es espacial. Se trata de movimiento sin número donde no hay distinciones, donde nada puede ser discriminado; un movimiento innumerable sin antes ni después. Crea la sensación de que nada más cabe que esperar perderse en él, abismo sin fondo de una divinidad desierta y silenciosa, soledad misma de Dios y su mutismo.

El tercer laberinto es espacial; Eco lo denomina manierista. Es el laberinto de la modernidad; puede el lector perderse en él pero dispone del método, son posibles la prueba y el error. Obviamente, la estructura de la biblioteca abacial obedece a este modelo: Adso y Guillermo se pierden, pero hay un método. Finalmente, la puerta del espejo les revela el secreto. 
La trama laberíntica se escande en las tres incursiones que Adso y Guillermo, juntos, efectúan en búsqueda del secreto de la biblioteca de la Abadía. Búsqueda conjeturable en el marco aristotélico de las tres ciencias teoréticas: la del ente móvil, la matemática —o «ciencia de la identidad entre las cosas que nosotros conocemos y las que se conocen de modo absoluto"— y la filosofía primera, que requiere ir más allá de las imágenes móviles que el espejo devuelve a los desprevenidos que enfrentan la puerta abroquelada debajo del sensus litteralis y la suppositio materialis: «age primum et septimum de quatuon.

Es obvio que la puerta del espejo — que obtura o franquea el acceso al finis Africae desde la biblioteca - devuelve los propios ídolos de quienes la enfrentan, así como el lenguaje en su nuda literalidad, marginada la letra de sus sentidos espirituales, espanta agitando espectros deformes de nosotros mismos. Algo semejante sucede con los sentidos espirituales marginados de la letra: engendran espejismos vacíos de todo contenido, víctimas de una orfandad sin territorio que tan sólo reflejan nuestra indigencia de palabras. Apropiarse del sentido literal abre la puerta y franquea el paso alegórico hacia lo que debemos creer, el tropológico hacia aquello que debemos hacer y la anagogía, que nos revela el sentido y dirección de nuestro deseo.

Littera gesta docet: en el texto, la prima significatio; en el comentador del texto, la prima expositio, en el lector, el primus intellectus, en todos los casos sinónimo de historia. Para S. Isidoro de Sevilla simplex locutio, quae ita ut dicitur intelligitur (Liber de variis quaestionibus, XI, $\mathrm{n}^{\circ} 4$ ). Una asimilación de historia a letra, al aspecto exterior sensible de las cosas por oposición a otro aspecto más profundo, imperceptible para los sentidos corpóreos y accesible únicamente para la inteligencia. Inteligencia que requiere la letra, no menos que la letra requiere ser inteligida. La letra - age primum et septimum de quatuor - desobtura el pasaje a los otros sentidos. En el ahí del umbral se reconcilian los cuatro sentidos de la escritura, sólo entonces se muestra su sentido completo y cuadriforme.

Una vez desenredados el laberinto de Teseo — la historia policial, leyendo hasta el final - y el manierista — la biblioteca, otro laberinto y otra historia- queda, entonces sí, el rizoma sin entrada y sin salida. Es un laberinto temporal. Se inaugura con la ecpírosis del finis Africae y finalmente consume la biblioteca toda y la Abadía; determina la separación irreversible de Guillermo y Adso portando muñones de la biblioteca original. No está narrado, no puede narrarse. No debe confundirse con aquellos laberintos que construye el lector para sí mismo cuando, rechazado por sus propios ídolos y a causa de ignorar el hic et nunc de la narración, aquella cruz que hace posibles todas las historias, cree que no hay allí historia alguna. Sumergido en esa confusión, es probable que desee, como Adso, confundido y agobiado, perderse en la divinidad desierta y silenciosa: desierta y silenciosa por la separación irreconciliable de los sentidos literal y anagógico. Sin embargo eso acontece más allá de la narración, no en ella.

\section{El nombre de la rosa}

\section{1. «Contrafacta non sunt argumenta...»}

Guillermo de Baskerville dice que él y sus hermanos franciscanos aconsejaban al Emperador, al igual que su homónimo de Ockham y Marsilio de Padua lo hicieron con Luis de Baviera. 
Propiciaban la separación de los poderes espiritual y temporal, la relativa soberanía del poder temporal del emperador, la pobreza apostólica y el derecho subjetivo. Con Marsilio se afianzó un naturalismo fisicista que hizo de la sufficientia vitae un principio de fundamentación social de la civitas, se produjo un abandono progresivo del fundamento político de la comunidad y, con ello, también el nacimiento de una sociedad cimentada en la naturalidad de la condición precaria del hombre que requiere agruparse para dar satisfacción a sus necesidades. A su vez, Guillermo de Ockham postulaba el origen del poder en Dios, quien lo concedía al hombre por vías diversas en lo próximo, por la condición de homo viator. Cristo eligió a sus Apóstoles de manera inmediata, pero en el caso del poder temporal en el siglo XIV, si bien proviene de Dios y depende de él, la institución corresponde a la comunidad de los hombres que tienen derecho a elegir: el poder temporal es autónomo del poder espiritual, y ciertos gestos como la bendición papal del emperador se entienden como una deferencia de éste hacia aquél.

Así, la naturalización de la política por vía de la necesidad de satisfacción de la vida y la autonomía del poder temporal, junto con la impronta humana en la institución de la autoridad civil del gobernante, constituyen características protomodernas de la filosofía política que Eco exhibe en su novela. En ella fueron posibles la narración, la trama policial, los debates sobre la pobreza evangélica y el poder temporal. En la narración de los hechos y en los hechos narrados, se instala el deseo eudemónico de la ética aristotélica, aunque desprovisto ya de su aura política, asociado a la satisfacción de las necesidades de la vida y entregado a la voluntad institutiva de la comunidad humana.

En El nombre de la rosa, allí donde late el corazón de la modernidad en ciernes, late asimismo el segundo libro de la Poética. La risa constituye el fulcro donde Eco dirime la polémica entre los dos poderes: aptitudo ridendi que, como proprietas humanae naturae, constituye lo que del hombre puede saberse a ciencia cierta según criterios aristotélicos. Una eudaimonía restringida a la satisfacción de necesidades de la vida, una polis transfigurada en sociedad donde la política es filosofía social, y un libro con mucha autoridad que dice que es propio del hombre reír, son lo que hace que el hombre, riéndose, deconstruya la auctoritas y se apropie socialmente del poder temporal.

Para poder narrar esta transfiguración verdaderamente copernicana se requirió desvincular lo literal de lo anagógico, la res gesta de la sursum ductio. Para conseguir esa desvinculación hay que desvanecer los sentidos alegórico y tropológico que vinculan respectivamente la letra con aquello que puede saberse y debe hacerse. Una vez desvanecidas las mediaciones simbólicas quedan desvinculados la letra y el deseo eudemónico. Restan lo espiritual y lo literal, el fin último y la condición indigente del homo viator que se asocia con sus semejantes para satisfacer necesidades vitales.

Si no hubiese existido la Abadía sin nombre, acaso habría hallado Adso un nombre para su deseo y encontrado Guillermo el libro segundo de la Poética de Aristóteles. Incluso también habría conservado el Abad el honor de su abadía sin homicidios y Jorge la integridad de la auctoritas y la de la biblioteca. En pocas palabras El nombre de la rosa tampoco habría existido. 
Sin embargo, contrafacta non sunt argumenta. Lo único que hay es lo que literalmente consta en el texto de Eco y los actos de lectura, competentes o no, ejercidos sobre aquél: ¿qué pensar de la pobreza de la Iglesia o los debates en torno al poder temporal del papado?

Obviamente, es lícita la metátesis entre Jorge de Burgos y Jorge Luis Borges «porque las deudas se pagan» (Eco, [1984] 1987). No menos, porque el mismo acreedor confesó: «He cometido el peor de los pecados (...) No he sido feliz» (Borges, 1976). La puerta del espejo abroquelaba el secreto de la biblioteca. La ceguera de los bibliotecarios resistía la satisfacción de leer: «Nadie rebaje a lágrima o reproche // esta declaración de la maestría // de Dios, que con magnífica ironía // me dio a la vez los libros y la noche» (Borges, 1960).

La hermenéutica del deseo corresponde a la dimensión espiritual anagógica de la letra, que San Buenaventura caracterizó como una suerte de elevación «quasi sursum ductio». ${ }^{7}$ ¿Qué deseos alientan en los debates sobre la pobreza de la iglesia y el poder temporal del papado?

El desvanecimiento de las mediaciones simbólicas sucede hacia el final de la novela. Quatuor en su literalidad es un deíctico que indica cómo abrir la puerta del espejo y franquea el acceso al finis Africae. Y el finis Africae constituye el ápice del edificio cuyo inferior es el refectorio donde Adso se encuentra con la muchacha sin nombre. Por ello, quatuor también cumple la función de indicar hacia lo alto, hacia donde Guillermo y los demás monjes buscan palabras que nombren el deseo eudaimónico de cada uno de ellos. Se trata de un deíctico anagógico. Para Aristóteles significaba el ejercicio virtuoso de la razón; en los tiempos que Eco asigna a su relato designaba ya cierta sufficientia vitae. Acaso los protagonistas de la escena última del finis Africae encarnen los cuatro sentidos de la Escritura: Guillermo el literal, por sus apabullantes competencias semióticas; Abbone el alegórico, por la elocuencia metafórica de su «lenguaje de las gemas» atesoradas en la cripta de la iglesia; Jorge el tropológico, por el celoso disciplinamiento moralizante de la risa que deconstruye la auctoritas; Adso el anagógico, por buscar nombre para su deseo. ${ }^{8}$

Derívanse algunas conclusiones:

1) El Abad muere asfixiado. Con él perece el sentido alegórico: queda reducido a la literalidad de las gemas sepultas en la cripta de la iglesia.

2) También muere Jorge por su propia determinación al devorar literalmente el libro prohibido y envenenado. Con él perece el sentido tropológico: el segundo libro de la Poética queda reducido a la literalidad en el acto de su deglución.

3) Mantiene salvos a Guillermo y Adso. Con ellos perduran los sentidos literal y anagógico, el primero y el último de los cuatro. La expresión «age primum et septimum [i.e. ultimum] de quatuon indica el orden semiótico y político que se avecina (via nova). Solamente esos dos sentidos permanecen: «lo que la letra dice» — facta hominum —, y «aquello que la letra quiere decir», interpretada por el deseo —anagogicus indicium - . La letra gesta docet, y no se accede al sentido anagógico sin las mediaciones simbólicas desvanecidas.

El deseo queda privado de su sostén deíctico: «Hay demasiada confusión aquí» — dijo Guillermo-. "Non in commotione, non in commotione Dominus» (Eco, [1980] 1985: 597). Son las líneas finales que cierran la noche del séptimo día y las últimas palabras de Guillermo en la narración. Constituyen un deíctico de los nuevos tiempos políticos que ya han comenzado. 


\section{Notas}

${ }^{1}$ G. de Ockham, Breviloquium de potestate papae, L. Baudry (Ed.) (1937), J. Vrin, Paris, pp. 101, 106, 107 respectivamente: "Quod imperium romanum non est a papa», "Oppinio quod romanum imperium est a populo" $\mathrm{y}$ "Oppinio quod romanum imperium est a solo Deo».

${ }^{2}$ G. de Ockham, op. cit., p 119: «Per verba Christi et gesta ac doctrinam apostolicam et evangelicam probatur aperte, quia Christus et apostoli verbis et gestis expresse mostraverunt se illos imperatores infideles tanquam veros imperatores habuisse».

${ }^{3}$ G. de Ockham, op. cit., p 102: "Christus enim et Apostoli nequaquam docuerunt quod imperator romanorum tenebatur cognoscere imperium romanum esse a papa plus quam rex Franciae vel alius quicumque rex mortalis quia istud nec docuerunt explicite neque implicite».

${ }^{4}$ G. de Ockham, op. cit., p 127: «Quare relinquitur quod Apostoli a Christo non maiorem receperunt potestatem super romanos quam super alias nationes. Quare papa non plus iuris habet a Christo super imperatorem romanorum quam super reges quoscumque. Quod eciam patet ex hoc quod, saltem tempore Christi et apostolorum, omnia alia regna de iure et de facto romano imperio subjecta fuerunt et imperator romanorum erat dominus omnium aliorum. Sed Christus non dedit beato Petro vel alicui apostolo maiorem potestatem super dominium regum quam super reges sibi subjectos. Ergo non maiorem tribuit potestatem beato Petro vel successoribus eius super romanos quam super ceteras nationes nisi quoad hoc quod, quando romani pontifices romanis et non alus spiritualia seminarent, pro sustentatione sua et sui executione officii specialiter ipsorum metere valerent carnalia».

${ }^{5}$ G. de Ockham, op. cit., p 20: «Si papa per preceptum et ordinationem Christi talem haberet plenitudinem potestatis ut omnia tam in temporalibus quam in spiritualibus sine omni exceptione posset de jure que non obviant legi divine neque juri naturali, lex christiana esset horrendissime servitutis et incomparabiliter majoris quam fuerit lex vetus».

${ }^{6}$ Vitiello, V. (1999), Vico: Storia ideale eterna e lingua eroica, texto multicopiado de la conferencia I, correspondiente al seminario «Historia o Filosofía de la Historia?», Buenos Aires, Universidad Nacional de Gral. San Martín, 2-4/9/99, passim.

7 S. Boenaventurae Opera Omnia, Col. Bonav, Quaracchi, Romae (1891): Breviloquium, Prologus, IV, 4: «Praeter litteralem sensum habet [Scriptura] tripliciter, scilicet allegoricus, moralis et anagogicus. Est autem allegoria, quando per unum factum indicatur aliud factum, secundum quod credendum est. Tropologia sive moralitas est, quando per id quod factum est, datur intelligit aliud, quod faciendum est. Anagogia, quasi sursum ductio, est, quando datur intelligi illud quod desiderandum est, scilicet aeterna felicitas beatorum».

${ }^{8}$ En su recensión a la primera novela de Eco, Nunzia Rossi (1985), Un libro prohibido, en: Renato Giovannoli (Ed.), Ensayos sobre "El nombre de la rosa», Barcelona, Lumen, pp 300-334, asocia NR a los cuatro sentidos de la escritura, tal como lo hace Dante en su famosa carta XIII al Can Grande de la Scala. Excluye, sin embargo, la posibilidad de un nivel anagógico. 


\section{Referencias bibliográficas}

Bonaventure, S. (1882). Opera Omnia. Collegium S. Bonaventurae (Rome, Italy) [en línea] Consultado en junio 2016 en: https://archive. org/search.php?query=creator $\% 3 \mathrm{~A} \% 22 \mathrm{Bonaventure} \% 2 \mathrm{C}+\mathrm{Saint} \% 2 \mathrm{C}+$ Cardinal\%2C+ca.+1217-1274\%22

Borges, J.L. (1989-1996). Obras Completas. Buenos Aires: Emecé.

Alighieri, D. (1996). Lettera a Cangrande. Biblioteca dei Classici italiani di Giuseppe Bonghi (Traducción: Adele Garavaglia) [en línea]. Consultado en junio de 2016 en: http://www.classicitaliani.it/dante/cangran.htm Eco, U. ([1980] 1985). El nombre de la rosa. (Traducción al espańol: Ricardo Pochtar). Barcelona-Buenos Aires: Lumen-De la flor.

([1984] 1987). Apostillas a «El nombre de la rosa» (Traducción al español: Ricardo Pochtar). Barcelona-Buenos Aires: Lumen-De la flor. Оскнам, G. (1967-1986). Opera philosophica et theologica [cura Instituti Franciscani universitatis S. Bonaventurae]. St. Bonaventure, NY: St. Bonaventure University.

Vitiello, V. (1999). Vico: Storia ideale eterna e lingua eroica, texto multicopiado de la conferencia I, correspondiente al seminario «¿Historia o Filosofía de la Historia?», Buenos Aires, Universidad Nacional de San Martín, 2-4/9/99.

\section{Corti, Enrique C.}

